\title{
Phlegmonous gastritis following coronary bypass surgery
}

\author{
J Radhi MB ChB FRCPC, M Kamouna MB ChB, J Nyssen PhD
}

J Radhi, M Kamouna, J Nyssen. Phlegmonous gastritis following coronary bypass surgery. Can J Gastroenterol 1999; 13(10):837-839. Phlegmonous gastritis is a rare, rapidly progressive and potentially fatal gastric bacterial infection. A case of phlegmonous gastritis following a coronary bypass surgery is described. This condition was not diagnosed premortem due to the nonspecific nature of the gastrointestinal symptoms. Upper gastrointestinal endoscopy may be of value in establishing the diagnosis in emergencies with culture of gastric aspirate and biopsy.

Key Words: Coronary bypass surgery; Endoscopy; Phlegmonous gastritis

\section{Gastrite phlegmoneuse faisant suite à un pontage coronaire}

RÉSUMÉ : La gastrite phlegmoneuse est une infection gastrique rare d'origine bactérienne, d'évolution rapide et potentiellement mortelle. Un cas de gastrite phlegmoneuse faisant suite à un pontage coronaire est décrit. Cette affection n'avait pas été diagnostiquée avant le décès du patient à cause de la nature non spécifique des symptômes gastro-intestinaux. Une endoscopie des voies digestives hautes accompagnée d'une culture du liquide gastrique et d'une biopsie peut s'avérer utile pour établir rapidement le diagnostic.
P hlegmonous gastritis is a rare disease with a high mortality rate. It has been described in association with peptic ulcer, gastric carcinoma, alcoholic liver disease, diabetes mellitus, invasive gastroscopic manipulation, oral intoxication with caustic substances, Sjögren's syndrome and acquired immunodeficiency syndrome (1-4). It is most often caused by streptococci, and other organisms such as staphylococci, Escherichia coli, pneumococci, enterobacter and Klebsiella species have also been implicated. Prompt recognition of phlegmonous gastritis by endoscopic biopsies and bacteriological sampling may improve the prognosis of these patients (5).

\section{CASE PRESENTATION}

A 75-year-old man with a known history of an anterior wall myocardial infarction in 1993 was admitted for coronary artery bypass surgery. Coronary angiography demonstrated depressed ventricular function and severe double vessel disease.
He underwent triple coronary artery bypass graft surgery. Three days after surgery he complained of abdominal discomfort, accompanied by episodes of coffee ground emesis and melena. Laboratory investigation revealed a hemoglobin level of $110 \mathrm{~g} / \mathrm{L}$, white blood cell level of $17.5 \times 10^{9} / \mathrm{L}$ and urea level of $8.1 \mathrm{mmol} / \mathrm{L}$, and electrolyte levels were normal. The patient died of respiratory and cardiac arrest. Past medical history revealed recurrent angina, cerebrovascular accident, hypertension and seizure attacks. His medication included dilantin, captopril, warfarin, nitroglycerin patch and diazepam.

Autopsy examination revealed an opened epicardium with intact triple bypass angioplasty. The heart was enlarged and showed old anteroseptal infarct. Both lungs were congested, but there was no evidence of consolidation or pulmonary embolism. The stomach contained $300 \mathrm{~mL}$ of altered blood. The mucosa was hemorrhagic and covered with green black exudate. The stomach was dilated, the wall appeared

Department of Pathology, College of Medicine, Royal University Hospital and University of Saskatchewan, Saskatoon, Saskatchewan

Correspondence and reprints: Dr JM Radhi, Royal University Hospital, Saskatoon, Saskatchewan S7N 0W8. Telephone 306-655-2221, fax 306-655-2223, e-mail radhij@sdh.sk.ca

Received for publication August 28, 1998. Accepted November 24, 1998 


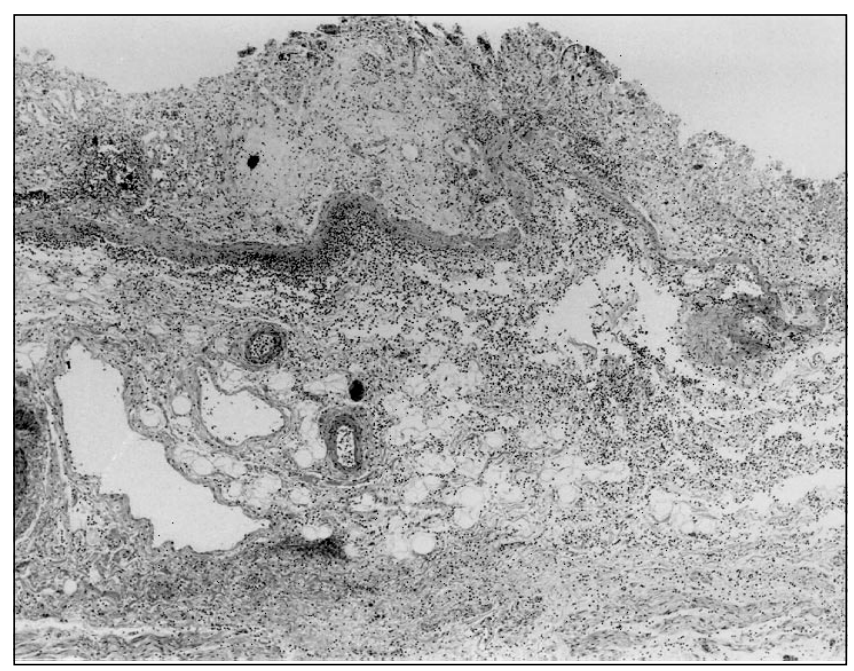

Figure 1) Phlegmonous gastritis showing transmural inflammation. Magnification $\times 125$

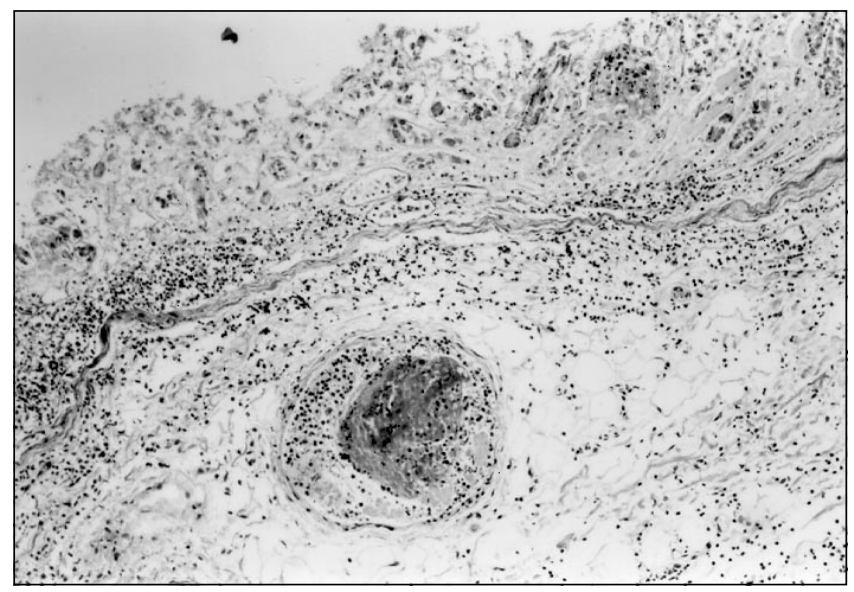

Figure 2) Photomicrograph demonstrating submucosal edema, and inflammation and vascular thrombosis. Magnification $\times 125$

thickened, and the serosa was pale and edematous. There was no evidence of peptic ulceration or malignancy, and no atheromatous changes of the celiac axis or its main branches. Microscopic examination showed mucosal necrosis, submucosal edema, vascular thrombosis and transmural inflammation with no muscle necrosis (Figures 1,2). Higher magnification showed a predominantly polymorphonuclear leukocyte infiltrate (Figure 3). Gram stain demonstrated Gram-positive diplococci and Gram-negative bacilli. The overall appearance was consistent with phlegmonous gastritis. Culture was not performed. The liver weighed $1300 \mathrm{~g}$ and showed severe chronic venous congestion with no cirrhosis. There was no evidence of any septic focus or other significant pathology.

\section{DISCUSSION}

Phlegmonous (suppurative) gastritis is the term used to describe acute suppurative inflammation of the stomach wall. The mortality associated with this disease continues to be high because it is often not recognized. This is in part due to

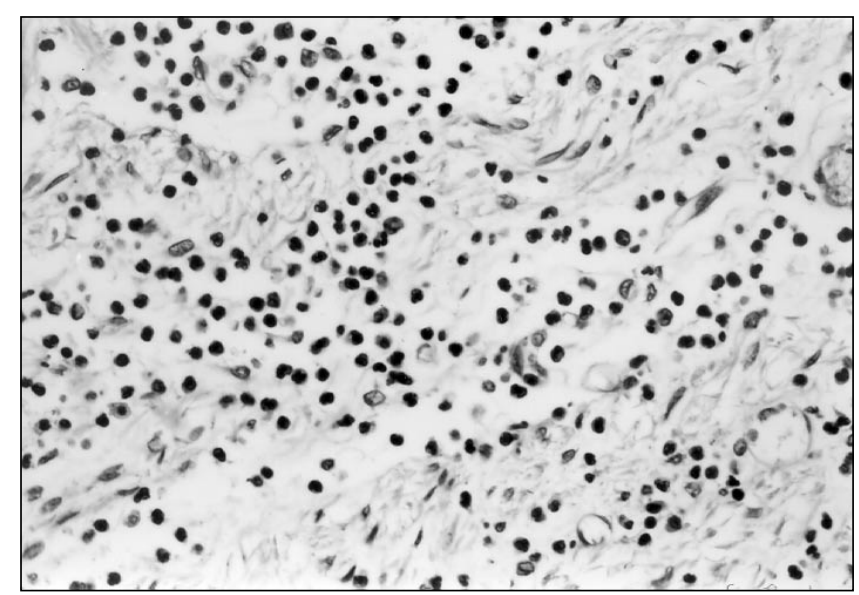

Figure 3) High power view showing submucosal edema and acute inflammation. Magnification $\times 310$

the lack of clinical suspicion, and nonspecific signs and symptoms. Most of the cases reported in the literature as well as this case were not suspected clinically, but rather were discovered at autopsy, or after studies of surgical specimens from patients in whom the diagnosis was not made preoperatively. Most cases involved patients in the 30 to 60 years age group, but there is a wide age range (6). Clinical features are usually of a rapid onset with upper abdominal pain, tenderness, nausea and vomiting, and rarely upper gastrointestinal bleeding. Physical findings often include fever, peritoneal signs and occasionally a palpable mass. Fever, chills and severe prostration are ominous signs of bacteremia and septicemia. Upper gastrointestinal tract endoscopy often shows a dilated stomach with edematous folds and rigidity of the antrum (7). Laboratory examination often reveals polymorphonuclear leucocytosis and occasionally positive blood culture $(1,8)$. Concomitant bacterial infection is often present in a variety of sites. Phlegmonous gastritis most commonly involves the stomach in a diffuse fashion, although the entire gastrointestinal tract may be affected (6). Occasionally a chronic form develops within the stomach wall due to organization of the acute inflammatory exudate and fibrosis (9).

Histological examination demonstrated acute inflammation of the submucosa with extension to the muscle coat and the serosa. Thrombosed vessels are commonly found in the edematous submucosa.

Alpha-hemolytic streptococci are the organisms most frequently implicated. Other organisms such as staphylococci, pneumococci, E coli, enterobacter, Klebsiella species and Clostridium perfringens have also been isolated (4). Mixed bacterial infections have been reported. No culture was performed in this case.

Our patient developed gastric symptoms following bypass surgery, complicated by gastric bleeding. The pathogenesis of this condition remains unclear. It has been suggested that bacteria may enter the gastric mucosa after mucosal injury. In some cases there is a pre-existing gastric pathology such as peptic ulcer or carcinoma that might permit entry of micro-organisms. It is not known by which route the infection 
is acquired. One possibility is direct spread from the gastric lumen due to ingestion of infected respiratory tract secretion, in which case acute or chronic gastritis may act by reducing acid secretion and providing a portal of entry through damaged mucosa. This is the most likely explanation for the phlegmonous gastritis in this patient. The second route is blood-borne infection spread to the stomach from a distant focus $(9,10)$. However, autopsy did not reveal any other site of infection in this case.

The literature includes reports of phlegmonous gastritis associated with alcoholic liver disease, diabetes mellitus, Sjögren's syndrome, human immunodeficiency virus-1 seroconversion and adult $T$ cell leukemia $(1,2,11)$. The increased risk in these patients is related to an innate susceptibility. Most patients succumb because of septicemia. The disease may appear to be confined to the stomach in the early stages; however, subsequent spread to the rest of the gastrointestinal tract may follow. Although this is an extremely rare condition, clinicians need to be aware of this condition because the prognosis is related to the speed of recognition and the treatment. The overall mortality rate is $67 \%$. Partial or total gastrectomy combined with antibiotic therapy is the most appropriate regimen and is reported to reduce mortality in about $20 \%(10)$.

\section{REFERENCES}

1. Zazzo JF, Troche G, Millat B, Aubert A, Bedossa P, Keros L. Phlegmonous gastritis associated with HIV-1 seroconversion. Endoscopic and microscopic evolution. Dig Dis Sci 1992;37:1454-9.

2. van Leeuwen ML, Tjiong HL, van Blankenstein M, Mulder AH, Bakker CM. Phlegmonous gastritis: an unusual presenting symptom of Sjören's syndrome. Gut 1993;34:1142-4.

3. Ross DA, Vincenti AC. Acute phlegmonous gastritis: a rare condition with a potentially common cause. Br J Hosp Med 1994;52:115-6.

4. Mittleman RE, Suarez RV. Phlegmonous gastritis associated with the acquired immunodeficiency syndrome/pre-acquired immunodeficiency syndrome. Arch Pathol Lab Med 1985;109:765-7.

5. Miller AI, Smith B, Rogers AI. Phlegmonous gastritis. Gastroenterology 1975;68:231-8.

6. Sloan JM, Correa P, Lindeman J, et al. The stomach, In: Whitehead R, ed. Gastrointestinal and Esophageal Pathology. Philadelphia: Churchill Livingstone, 1989:385-40.

7. Schultz MJ, Van der Hulst RW, Tytgat GN. Acute phlegmonous gastritis. Gastrointest Endosc 1996;44:80-3.

8. Blei GD, Abrahams C. Diffuse phlegmonous gastroentrocolitis in patient with infected peritoneo-jugular venous shunt. Gastroenterology 1983;84:636-9.

9. O'Toole PA, Morris JA. Acute phlegmonous gastritis. Postgrad Med J 1988;64:315-6.

10. Haubrich WS, Schaffner F, Berk JE. Gastroenterology, vol 1, 5th edn. Philadelphia: WB Saunders Company, 1995:807-8.

11. Takeuchi M, Uno H, Matsuoku H. [Acute necrotizing gastritis associated with adult T-cell leukemia in the course of chemotherapy]. Gan To Kagaku Ryoho 1995;22:289-92. 


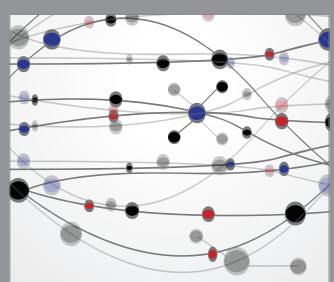

The Scientific World Journal
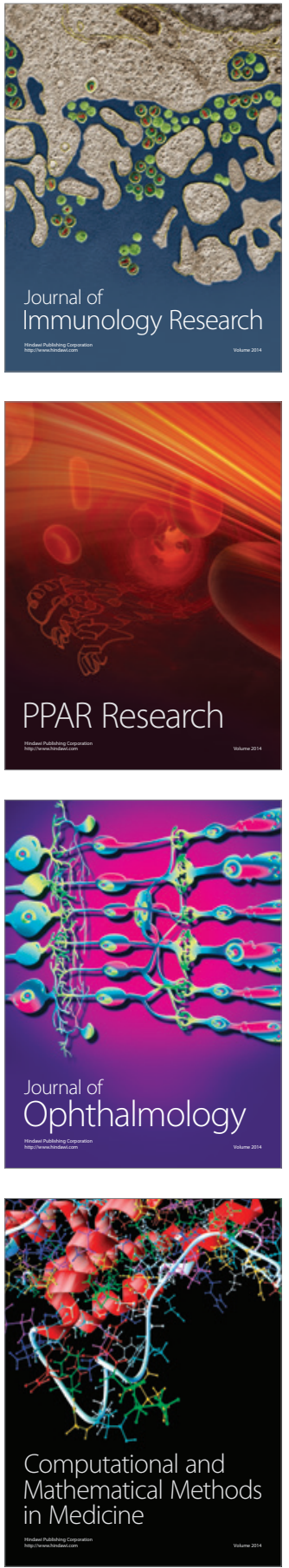

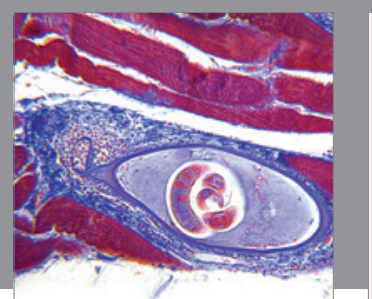

Gastroenterology Research and Practice

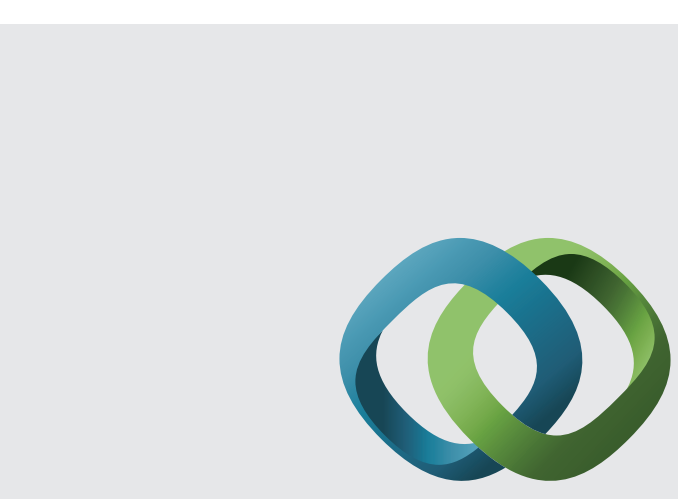

\section{Hindawi}

Submit your manuscripts at

http://www.hindawi.com
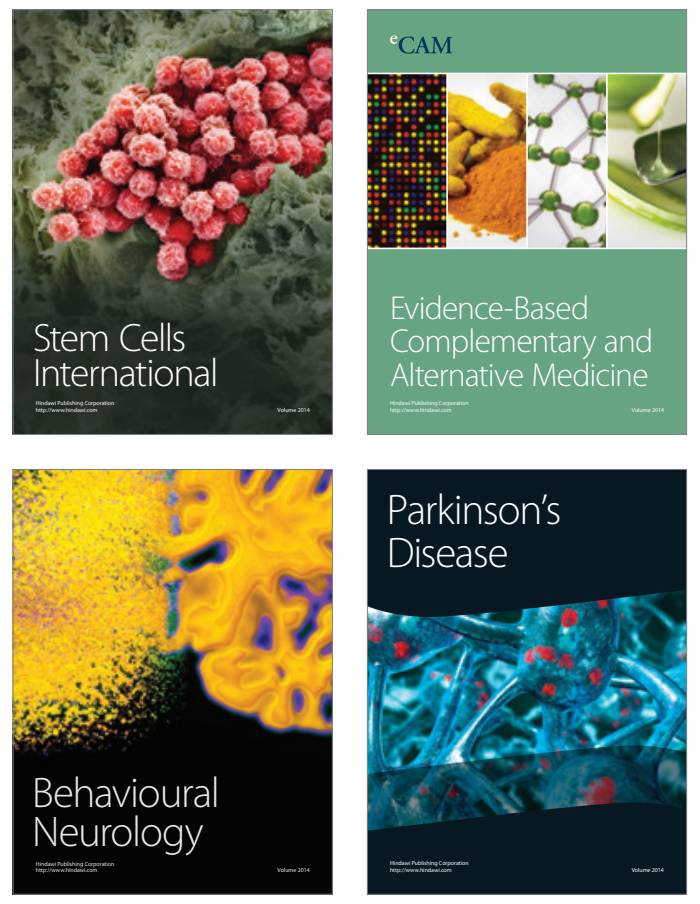
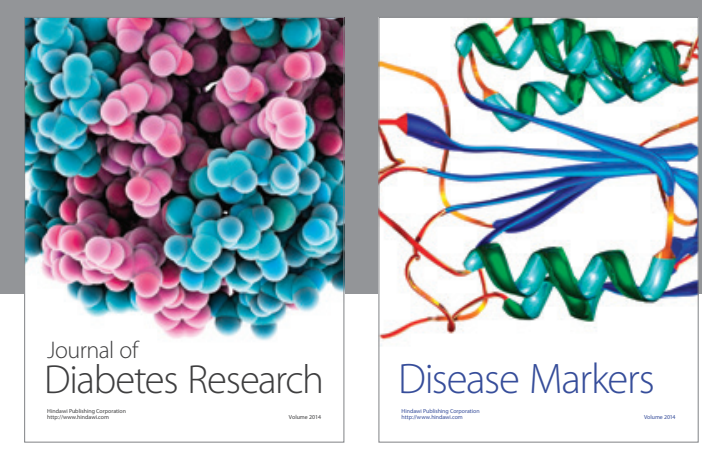

Disease Markers
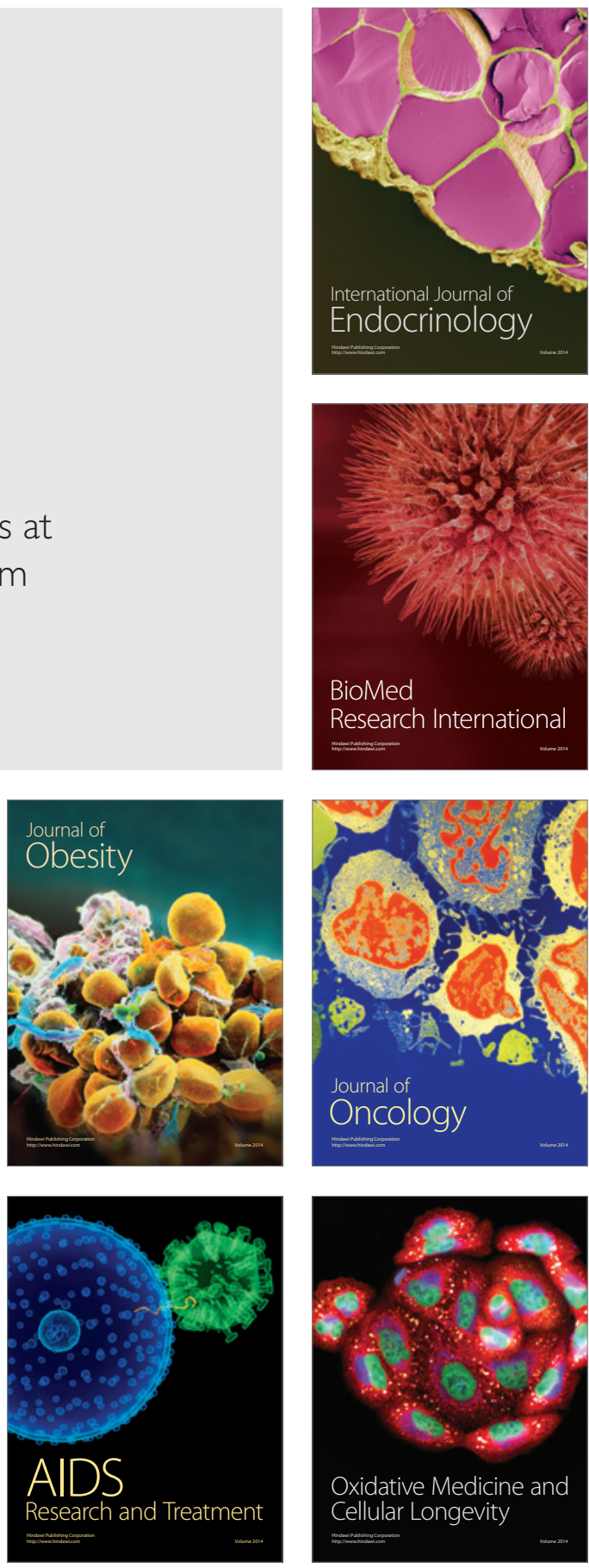